Review Article

\title{
EVALUATION OF THE INDIAN TOP 10 PHARMA EDUCATION INSTITUTIONS RESEARCH OUTPUT LISTED BY NATIONAL INSTITUTIONAL RANKING FRAMEWORK (NIRF) 2020: A SCIENTOMETRIC STUDY
}

\author{
MALLIKARJUN KAPPI ${ }^{*}$, MADHU S. ${ }^{2}$, BALABHIM SANKRAPPA BIRADAR ${ }^{3}$
}

1,2Reseach Scholars Department of Library and Information Science, Kuvempu University, Shankarghatta, Shimoga, ${ }^{3}$ Department of Library and Information Science, Kuvempu University, Shankaraghatta, Karnataka, India

Email: mkmallikarjun@gmail.com

Received: 06 Apr 2021, Revised and Accepted: 14 May 2021

\begin{abstract}
The Higher Education System Rankings measure national higher education systems and meet a long-standing need to shift the discussion from the ranking of the NIRF top institutions to the best overall systems in each country, to reflect the country's overall performance in NIRF rankings we propose a new Excellence/Quality indicator based on the excellence level reached by their Top Pharma education institutions within the Top positions of the NIRF weighted by the country's size population. In the present study, we analyzed the Top 10 Pharma education institutions of the NIRF Ranking 2020. The first rank positioned by Hamdard University NIRF score of (80.5). SCOPUS database was used to extract the data and the study was limited to five years (2016-2019) which resulted in 7172 documents. The data analysis was performed using Biblioshiny, Microsoft excel, and VOS Viewer software, further data were explored using the bibliometrics tools and techniques. The study attempt to measure the top 10 Pharma Education Institution's and their publications, Year-Wise distribution of research Output, document type, Highly Prolific Authors, Most Preferred Sources, Funding Agencies, Most Cited Papers, Most Productive and Most Cited Countries, and Highly Prolific Keywords based on the collected data. The analysis of the study indicates the highest publications with 2129, published by Institute of Chemical Technology-Mumbai; the most the productive year 2017 with 1508 publications; most of the publications are published as articles (6067); highly prolific author Sekar N with 194 papers, total citation 1954, h-index 22; preferred source title RSC Advance, 217 paper, total citation 2508, h-index 24; top funding agency University Grant Commission (UGC) 609 papers; top cited paper Shao Y, 2015, Molecular Physics; most productive and most cited country the USA.
\end{abstract}

Keywords: Scientometric study, Research output, National institutional ranking framework, NIRF, Pharma education, SCOPUS

(C) 2021 The Authors. Published by Innovare Academic Sciences Pvt Ltd. This is an open access article under the CC BY license (https://creativecommons.org/licenses/by/4.0/) DOI: https://dx.doi.org/10.22159/ijpps.2021v13i7.41709. Journal homepage: https://innovareacademics.in/journals/index.php/ijpps.

\section{INTRODUCTION}

Higher education institution makes a big impact in developing knowledge foundation and to provide best educational practices in changing scenario. So, for any country reputation of higher education institutions matters a lot because they provide knowledge and dignity that makes an individual self-confident personality with a well-balanced carrier [1-3]. To ensure the qualities and standards, adequate funds from government and private funding agencies, and other resources play a significant role in all forms to improve the institution status. To assess the higher education system of universities and institutions various ranking systems emerged around the world from 2003. Some of the well-known ranking system "The Academic Ranking of World Universities (ARWU) of the Institute of Higher Education by Shanghai Jiao Tong University; 'The Times Higher Education World University Rankings of Times Higher Education' (Times) from the UK and 'QS World University Rankings of Quacquarelli Symonds (QS)' UK'. These systems are an effective way of measuring the education institution. By setting a qualified benchmark to access the quality and performance of the institution, also provides free publicity worldwide, and also it can be called has best branding practice of higher education institutions. This resulted in means of selecting the best institution by students and researchers to pursue educational and research carrier in best of the best institution around the world [4].

In India due to the rapid growth of higher educational institutions started emerging numerous numbers in different states, different institutions and different domain like Universities, Degree colleges, Engineering, Architecture, Pharmacy, Management, Law, Medical and Dental colleges and Agriculture where the quality as well standard of institutions matters the most in the country to portray top Universities or Institutions by using some ranking systems. To access the quality of activates of institutions Government of India introduced an Indian ranking system named has 'The National
Institutional Ranking Framework' (NIFR) on 29th September 2015 under 'Ministry of Human Resource Development (MHRD)'. By accessing based on definite five parameters consist of Teaching, learning and resources ranking weight age of (30\%), Research and Professional Practices weight age of (30\%), Graduation outcomes weight age of (20\%), outreach and Inclusivity weight age of $(10 \%)$ and Perception weight age of (10\%) and started ranking from 2016. Rankings show what universities in our community are doing and are an opportunity to shed light on the activities and efforts of other institutions not covered by the rankings. This allows us to prove how universities make a difference in the world we live in.

HRD Minister, Ramesh Pokhriyal announced the 2020 NIRF rankings on June 11, 2020. For the 2020 ranking process under the overall category or domain-specific category total of 5805 applicant institutions were enrolled for the ranking process. After scrutinizing the process unique applicant institutions of 3771 were further shortlisted. The highest of institution enrolled were General Degree colleges of (1659) followed by Engineering Institutions (1071), Management Institutions (630), Pharmacy Institutions (334), Universities Institutions (294), Medical Institutions (118), Law Institutions (97) and lastly Architecture Institutions (48). Compare to the previous year applicant institutions were gradually increased from (3127) in 2019 to (3771) in 2020 with an increasing number of (644) applicant institutions in 2020.

The pharmaceutical industry is currently one of the most dynamic of all industries [5] and there are 1,211 pharmacy institutes in India, of which MHRD publishes a list of top institutes based on a set of parameters also mentioned here. This scientometrics study helps to know the top Pharmacy colleges in India as per NIRF ranking 2020. "Research productivity reflects the excellence in academic institutions, where publications of articles in good academic journals are the opportunity for every individual and institution to get a good score and top ranks" [6] to identify the research and development activities 
in higher education. NIRF system has given the second priority under the parameter of 'Research and Professional Practices' where marks are divided into four major components as Institution publication metrics, Quality of publication metrics, IPR grants and Patents, Project footprints, and best Professional Practices. Where NIRF framework used third-party databases Scopus and Web of Science (WOS) for retrieving publication and citation data. And also used Derwent Innovation for retrieving data related to patents. The present study intent on the research output of pharma institutions among the top ten NIRF ranked institutions in 2020.

\section{Review of literature}

A NIRF bibliometric study by Mukherjee and Marisha et al., [7-8] on central universities of India to investigate the perception of the facet on research and professional. The data ware extracted from three leading databases, such as Web of Science (WOS), Scopus, and India citation Index. The results of the study show that the number of research results that should be considered indicators of the performance of research institutions in any international database is not exhaustive and seems incredible. It appears that no single database can fully cover all of the institute's research results. In general, an international database contains only $80 \%$ of research articles and only shows the result produced by scientific and applied sciences. Social sciences, arts, and humanities are ignored in these databases. Among these institutions, cooperation between countries is more prominent than international collaboration. However, most of the research results appear in journals with an impact factor (JCR) in the range of 1-3. Although each article by JNU authors has the least citations, they rank highest in the NIRF ranking, showing that citations have little effect on the NIRF ranking.

A comparative study by Reddy and others $[1,9]$ the status of higher education in India's emerging markets, high-impact research indicators, and world university rankings. They described the higher education system, government academic research programs, and related educational statistics compared with India and China among various academic research indicators (documents cited, number of citations, number of citations per document, and three types of $\mathrm{H}-$ index) and compare them on world university rankings. Our exploratory analysis shows that among the citable documents in the "All subjects" category, the United States ranks first, followed by China, the United Kingdom, and India ninth. In general, Indian universities are far behind Chinese universities in terms of world university rankings and research indicators.

Comparative studies conducted by $[4,10]$ Sheeja et al. and Kappi et al. These studies examined the relationship between academic output and institutional classifications based on the NIRF in India using the web of science database and official NIRF website, Times Higher Education World University Rankings, and QS World University Rankings. Analyzed and compared the NIRF parameters with those of the world's leading universities. The study found that the fixed parameters used for the evaluation of Indian institutions under NIRF are the same as those of other world university ranking institutions. The academic performance of a university is one of the main parameters of the university classification scheme. This article is the first attempt to find the relationship between academic productivity and Indian university rankings based on NIRF.

A Scientometric studies conducted by Pradhan B and Tapas Kumar Das $[11,12]$ on six IIT-Delhi, Kharagpur, Madras, Bombay, Kanpur, and Roorkee. The data were extracted from the Scopus database and both studies were limited to ten years. This resulted in that relation citation impacted more in IITs Roorkee and Bombay when compare to other IIT's. Authors of IIT Kharagpur works cited more when par to other IIT's. Physics of Plasma was the most used communication channel.

A study on Scientometric mapping was undertaken by Kumar, $\mathrm{S}$ and $\mathrm{R}$, Senthilkumar [13] to know the research output of the Indian Institute of Science (IISc) of NIRF top-ranked institution of 2019. The study was restricted to five years using Science Citation Index (SCI), further, the analysis aimed to find out the year-wise contribution in research, annual growth, specialized areas of research, a collaboration between institution and countries, forms of publications, funding agencies, communications channels, top authors, author's pattern, etc. using different standard Scientometrics tools and techniques to data interpretations. The studies were conducted by [6, 10] Kumar et al., 2019; Kappi and Biradar on Indian Universities to know the research impact of NIRF top 20 ranked universities. Data was collected using the web of science (WOS) bibliographic database and analysis was shaped using different bibliometric indicators. The impact of NIRF on publication output was consistently growing and there was $38 \%$ of growth in publication. Delhi University placed top in h-index. There was considerable growth in physical science and engineering-related branches.

Lwoga, Sangeda, And Sife [14] Scientometric analysis was conducted using Publish or Perish software to map online visibility of pharmaceutical research at Muhimbili United University of Health and Sciences (MUHAS) from 1981 to 2016. They collected 449 papers from 33 MUHAS scientists and analyzed them. using scientometric indicators, such as total citations, number of authors per publication, average citations per article, average citations per year, $\mathrm{h}$ index, g index, current $\mathrm{H}$ index (Hc index). and HI norm index. Studies have shown that since 1981, there has been a continuous increase in pharmacy publications on MUHAS. The level of collaboration between scholars is high and many publications have had a great impact through citations.

An evaluation study conducted on institutional research productivity by Pal and Sarkar [15] on Scientometrics, scientific visualization, and knowledge mapping of single-institutional studies and multi-institutional studies. The study compared global studies and Indian studies. Most of the studies used readily available (Scopus, Web of Science (WOS), INSPEC, MathSciNet, PubMed, and Indian Citation Index) abstracting and citation databases without considering the scrutinizing process and validation process of datasets. Especially in India single institutional studies more prevalent.

\section{Objectives}

The specific objectives are: To identify the research growth pattern of Pharma Education Institutions publications during 2015-2019; To find out Authorship Pattern, Collaboration Index (CI), Degree of Collaboration (DC), Collaboration Coefficient (CC), and Modified Collaboration Coefficient (MCC); To recognize the most collaborative institutions as well as the country in research; To know the highly prolific authors, citations received, an h-index of the prolific authors; To map the most preferred sources for publication; List out the top funding agencies and the most cited papers; To discover the most productive and most cited countries and observe the highly prolific keywords.

\section{Methodology}

The present study had undertaken pharm or pharmacy education institutions to know the research productivity of top-ranked NIRF institutions in the year 2020. The data was extracted on 07/09/2020 using Scopus citation and abstracting database the product of Elsevier. The search query was confined to AFFIL(India) AND AF-ID("Jamia Hamdard Faculty of Pharmacy" 60035251) OR AF-ID("University Institute of Pharmaceutical Sciences India" 60018483) OR AFID("National Institute of Pharmaceutical Education and Research Mohali" 60001411) OR AF-ID("Institute of Chemical Technology" 60006361) OR AF-ID("National Institute of Pharmaceutical Education and Research Hyderabad" 60110421) OR AF-ID("Birla Institute of Technology and Science Pilani" 60000414) OR AF-ID("Manipal College of Pharmaceutical Sciences" 60003299) OR AF-ID("JSS College of Pharmacy Mysore" 60107499) OR AF-ID("JSS College of Pharmacy Ooty" 60021359) OR AF-ID("National Institute of Pharmaceutical Education and Research Ahmedabad" 60110422) AND (LIMIT-TO (PUBYEAR,2019) OR LIMIT-TO (PUBYEAR,2018) OR LIMIT-TO (PUBYEAR,2017) OR LIMIT-TO (PUBYEAR,2016) OR LIMIT-TO (PUBYEAR,2015)) AND (LIMIT-TO (SUBJAREA,"PHAR") OR LIMIT-TO (SUBJAREA,"CHEM") OR LIMIT-TO (SUBJAREA,"BIOC") OR LIMIT-TO (SUBJAREA,"CENG") OR LIMIT-TO (SUBJAREA,"AGRI") OR LIMIT-TO (SUBJAREA,"IMMU") OR LIMIT-TO (SUBJAREA,"NEUR") OR LIMIT-TO (SUBJAREA,"HEAL") OR LIMIT-TO (SUBJAREA,"NURS") OR LIMIT-TO (SUBJAREA,"PSYC") OR LIMIT-TO (SUBJAREA,"VETE") OR LIMIT-TO 
(SUBJAREA,"DENT")). Search query resulted in 7172 documents and further, we processed using data mapping software Biblioshiny [16], Microsoft Excel, and VOSViewer [17] software's and all the data was explored using bibliometrics tools and techniques to meet the objectives of the study.

\section{LIMITATIONS}

The study was restricted to pharmacy institutes of NIRF top 10 ranked institutions using the "Research and Professional Practices" parameter and the research output study was restricted for the period (2016-2019) of five years.

\section{ANALYSIS AND DISCUSSION}

Authorship Pattern, Collaboration Index (CI), Degree of Collaboration (DC), Collaboration Coefficient (CC), and Modified Collaboration Coefficient (MCC)

\section{a) Collaboration Index (CI)}

The Collaborative Index (CI) methodology was proposed by [18] Lawani, 1980 . CI is the mean number of authors per paper. It can be calculated easily, but it cannot be interpreted as a degree because it has no upper-value limit. The formula is as follows:

$$
\mathrm{CI}=\frac{\sum_{j=1}^{k} j(f j \rrbracket}{N}
$$

In simpler terms,

$$
C I=\frac{(\mathrm{f} 1) 1+(\mathrm{f} 2) 2+(\mathrm{f} 3) 3+\cdots+(\mathrm{fn}) \mathrm{n}}{\mathrm{N}}
$$

Where, $\mathrm{f} 1, \mathrm{f} 2, \mathrm{f} 3 \ldots . .=$ number of authors

$\mathrm{N}=$ Total no of papers

Using data in table A, during 2015

$$
\begin{gathered}
C I=\frac{(22+242 * 2+258 * 3+\cdots+1 * 19)}{1289} \\
C I=\frac{5689}{1289} \\
C I=4.413
\end{gathered}
$$

Table A shows that CI was lowest (4.357) in the year 2018 and CI was highest (4.609) in the year 2019. The average CI was 4.448 during the study period.

\section{b) Degree of collaboration (DC)}

In current years, most of the countries have realized the significance of scientific research for its Socio-Economic Growth, and have started programs that encourage and support collaboration between researchers and scientists, both at the national and international levels. It can be defined as the number of multi-author publications in the discipline published during a year as against the total number of papers (multi-author and single author) published during the year. Degree of Collaboration propounded by [19], K (1983) as below:

$$
C=\frac{N m}{N m+N s}
$$

Using data in table 2, during 2015;

$$
\begin{gathered}
C=\frac{1267}{1267+22} \\
C=0.983
\end{gathered}
$$

Where $\mathrm{C}$ is the degree of collaboration, $\mathrm{Nm}$ is the number of multiauthored papers, and Ns is the number of single-authored papers. In the current study, the value of DC for the year 2015 is 0.983 which is the highest value of all the years and the average value of $\mathrm{C}$ is 0.97 .

\section{c) Collaborative Coefficient (CC)}

The CC was defined by [20] Ajiferuke, et al., Which was designed to remove the shortcomings of $\mathrm{CI}$ and $\mathrm{DC}$. The $\mathrm{CC}$ lies between 0 and 1 $(0 \leq \mathrm{CC}>1)$. As the number of single authors dominates, CC 0 . CC distinguishes between single-authored, two authored, threeauthored, etc. The problem with CC is that it does not give the value 1 for maximal collaboration except in the case where the number of authors is infinite. The collaborative coefficient is defined as (CC), the formula as below:

$$
\mathrm{CC}=1-\frac{\sum_{j=1}^{A}\left(\frac{1}{j}\right) f i}{N}
$$

Using data in table 2, during 2015

$$
\begin{gathered}
\mathrm{CC}=1-\frac{\left[(22)+\left(\frac{1}{2} * 242\right)+\left(\frac{1}{3} * 258\right)+\left(\frac{1}{4} * 229\right)+\cdots+\left(\frac{1}{19} * 1\right)\right]}{1289} \\
\mathrm{CC}=1-\frac{374.2337}{1289} \\
\mathrm{CC}=0.710
\end{gathered}
$$

The values of CC for year 2015, 2016 are 0.710 and 2017, 2018 and 2019 are 0.29 and $0.703,0.697$ and 0.706 respectively.

\section{d) Modified collaborative coefficient (MCC)}

The formula for the calculation of MCC is suggested by [21] Sarvanur and Srikanth (2010). CC gives 0 for single-authored papers, but it does not give the value 1 for maximal collaboration. This is taken care of by MCC. The formula as below:

MCC for distribution of authorships for 2015 in table A is calculated thus:

$$
\begin{gathered}
\kappa=\frac{A}{A-1}\left\{1-\frac{\sum_{j=1}^{k}(1 / j) f j}{N}\right\} \\
\kappa=\left(\frac{1289}{1289-1}\right)\left\{1-\frac{(1 \cdot 22)+\left(\frac{1}{2} * 242\right)+\left(\frac{1}{3} \cdot 258\right)+\left(\frac{1}{4} * 229\right)+\left(\frac{1}{5} \cdot 202\right)+\cdots+\left(\frac{1}{19} * 1\right)}{1289}\right\} \\
\mathrm{k}=(1.008)\left\{1-\frac{22+121+86+57.25+40.4+235+1157+6.125+3.22+1+1+0.67+0.31+0.07+0.067+0+0+0+0.053}{1229}\right. \\
\kappa=(1.008)\left(1-\frac{374.235}{1289}\right) \\
\kappa=(1.008)(1-0.29) \\
\mathbf{\kappa}=\mathbf{0 . 7 1 0}
\end{gathered}
$$

\section{NIRF 2020 ranked top ten pharma education institution's, place and NIRF scores}

The ranking assesses research-intensive universities across all their core missions: teaching, research, knowledge transfer, and international outlook. Table 1 discussed top-ranked institutions with the location of the institute situated. The study had covered only the top 10 pharmacy Institutes based on the overall criteria of the NIRF ranking system. By accessing based on definite five parameters constitute of 'Teaching-learning and resources ranking weightage'; 'Research and Professional Practices weightage'; 'Graduation outcomes weightage'; 'outreach and Inclusivity weightage' and 'Perception weightage'. Whereas Jamia Hamdard topped the position which is situated in New Delhi with a NIRF score of 80.5 and a 10th rank placed by JSS college of Pharmacy Mysore with a score of 64.58 .

\section{NIRF 2020 ranked top ten pharma education institution's} publications

The present study purely focused on "Research and Professional Practices weightage" further it has been subdivided into four parameters which are as follows: 1 . Publication metrics 2 . Metrics on quality of publication 3. IPR and Patents: Published and Granted 4. Projects and Professional Practice. where table 2 disclosed the research publication output of each institute from highest to lowest, where Institute of Chemical Technology (Mumbai) has made the highest contribution of 2129 publication followed by Birla Institute of Technology and Science (Pilani) of 1668 publications, Manipal College of Pharmaceutical Sciences (Udupi) of 1071 publications, Jamia Hamdard (New Delhi) of 984, National Institute of 
Pharmaceutical Education and Research (Mohali) of 703 publications and National Institute of Pharmaceutical Education and Research (Hyderabad) of 517, Panjab University (Chandigarh) of
504, National Institute of Pharmaceutical Education and Research (Ahmedabad) of 303, JSS College of Pharmacy (Ooty) and (Mysore) of 266.

Table A: Authorship pattern, collaboration index (CI), degree of collaboration (DC), collaboration coefficient (CC), and modified collaboration coefficient (MCC)

\begin{tabular}{|c|c|c|c|c|c|c|c|c|c|c|c|c|c|c|c|c|c|c|c|c|c|c|c|c|}
\hline Year & $\begin{array}{l}\text { Si } \\
\text { ng } \\
\text { le }\end{array}$ & $\begin{array}{l}\mathbf{T} \\
\mathbf{w} \\
\mathbf{0}\end{array}$ & $\begin{array}{l}\text { Thr } \\
\text { ee }\end{array}$ & $\begin{array}{l}\text { Fo } \\
\text { ur }\end{array}$ & $\begin{array}{l}\text { Fi } \\
\text { ve }\end{array}$ & $\begin{array}{l}\mathrm{Si} \\
\mathrm{x}\end{array}$ & $\begin{array}{l}\text { Sev } \\
\text { en }\end{array}$ & $\begin{array}{l}\text { Ei } \\
\text { gh } \\
t\end{array}$ & $\begin{array}{l}\mathbf{N i} \\
\text { ne }\end{array}$ & Ten & $\begin{array}{l}\text { Elev } \\
\text { en }\end{array}$ & $\begin{array}{l}\text { Tw } \\
\text { elve }\end{array}$ & $\begin{array}{l}\text { Thi } \\
\text { rtee } \\
\text { n }\end{array}$ & $\begin{array}{l}\text { Fou } \\
\text { rtee } \\
\text { n }\end{array}$ & $\begin{array}{l}\text { Fift } \\
\text { een }\end{array}$ & $\begin{array}{l}\text { Sixt } \\
\text { een }\end{array}$ & $\begin{array}{l}\begin{array}{l}\text { Sev } \\
\text { ent } \\
\text { een }\end{array} \\
\text {. }\end{array}$ & $\begin{array}{l}\text { Eig } \\
\text { hte } \\
\text { en }\end{array}$ & $\begin{array}{l}\text { Nine } \\
\text { teen }\end{array}$ & $\begin{array}{l}\text { To } \\
\text { tal }\end{array}$ & $\begin{array}{l}\text { CI } \\
\end{array}$ & DC & $\begin{array}{l}\text { CC } \\
\end{array}$ & $\begin{array}{l}\mathrm{M} \\
\mathrm{CC}\end{array}$ \\
\hline 201 & 22 & 24 & 258 & 22 & 20 & 14 & 81 & 49 & 29 & 10 & 11 & 8 & 4 & 1 & 1 & 0 & 0 & 0 & 1 & 12 & 4.4 & 0.9 & 0.7 & 0.7 \\
\hline 5 & & 2 & & 9 & 2 & 1 & & & & & & & & & & & & & & 89 & 13 & 83 & 10 & 10 \\
\hline 201 & 39 & 25 & 271 & 25 & 22 & 17 & 111 & 73 & 27 & 21 & 6 & 3 & 3 & 4 & 0 & 0 & 0 & 0 & 0 & 14 & 4.4 & 0.9 & 0.7 & 0.7 \\
\hline 6 & & 2 & & 7 & 6 & 5 & & & & & & & & & & & & & & 68 & 79 & 73 & 10 & 11 \\
\hline 201 & 36 & 29 & 321 & 23 & 20 & 15 & 126 & 68 & 27 & 18 & 10 & 9 & 2 & 3 & 0 & 0 & 0 & 0 & 0 & 15 & 4.3 & 0.9 & 0.7 & 0.7 \\
\hline 7 & & 2 & & 9 & 6 & 1 & & & & & & & & & & & & & & 08 & 83 & 76 & 03 & 03 \\
\hline 201 & 48 & 27 & 273 & 25 & 21 & 16 & 91 & 52 & 26 & 21 & 12 & 7 & 3 & 1 & 1 & 2 & 0 & 0 & 0 & 14 & 4.3 & 0.9 & 0.6 & 0.6 \\
\hline 8 & & 8 & & 4 & 6 & 2 & & & & & & & & & & & & & & 47 & 57 & 67 & 97 & 98 \\
\hline 201 & 58 & 21 & 299 & 25 & 22 & 14 & 92 & 66 & 43 & 27 & 9 & 11 & 6 & 3 & 4 & 1 & 1 & 3 & 1 & 14 & 4.6 & 0.9 & 0.7 & 0.7 \\
\hline 9 & & 2 & & 8 & 4 & 2 & & & & & & & & & & & & & & 60 & 09 & 60 & 06 & 07 \\
\hline
\end{tabular}

Table 1: NIRF 2020 ranked top ten pharma education institutions

\begin{tabular}{|c|c|c|c|}
\hline NIRF rank 2020 & Institution name & Place & NIRF score (out of 100) \\
\hline 1 & Jamia Hamdard & New Delhi & 80.50 \\
\hline 2 & Panjab University & Chandigarh & 79.80 \\
\hline 3 & National Institute of Pharmaceutical Education and Research & Mohali & 74.73 \\
\hline 4 & Institute of Chemical Technology & Mumbai & 74.50 \\
\hline 5 & National Institute of Pharmaceutical Education and Research & Hyderabad & 73.81 \\
\hline 6 & Birla Institute of Technology and Science & Pilani & 72.95 \\
\hline 7 & Manipal College of Pharmaceutical Sciences & Udupi & 67.42 \\
\hline 8 & National Institute of Pharmaceutical Education and Research Ahmedabad & Gandhinagar & 65.64 \\
\hline 9 & JSS College of Pharmacy & Ooty & 65.60 \\
\hline 10 & JSS College of Pharmacy & Mysore & 64.58 \\
\hline
\end{tabular}

Table 2: Pharma education institution's publications

\begin{tabular}{llc}
\hline S. No. & Institution name & Publications 2015-2019 \\
\hline 1 & Institute of Chemical Technology (Mumbai) & 2129 \\
2 & Birla Institute of Technology and Science (Pilani) & 1668 \\
3 & Manipal College of Pharmaceutical Sciences (Udupi) & 1071 \\
4 & Jamia Hamdard (New Delhi) & 984 \\
5 & National Institute of Pharmaceutical Education and Research (Mohali) & 703 \\
6 & National Institute of Pharmaceutical Education and Research (Hyderabad) & 517 \\
7 & Panjab University (Chandigarh) & 504 \\
8 & National Institute of Pharmaceutical Education and Research (Ahmedabad) & 303 \\
9 & JSS College of Pharmacy (Ooty) & 266 \\
10 & JSS College of Pharmacy (Mysore) & 266 \\
\hline
\end{tabular}

\section{Year-wise research output of pharma education institution's}

The extracted data further separated on the basics of year-wise research publication output on pharma educations institution which is analyzed in table 3 the present study is considered only to five years of data in the prescribed table from 2015-2019, where total publication of 7172 recorded and total citations cited by 50859 with h-index of 192. The highest publication output came in the year 2017 of 1508 publications and highest total citation came in 2019 of 20671 using annual citations of 1460 publications and the highest hindex 51 came in the year 2015 using 1289 publications.

\section{Document type}

In table 4 the extracted data further divided into different types of document article, review, Book chapter, conference paper, erratum, editorial material, note, letter, short survey, book, data paper, retracted, and undefined. Where major publications came through article 6067 (84.59\%) form, followed by review papers of 674 $(9.40 \%)$, book chapter $258(3.60)$, conference paper $61(0.85)$.

\section{Highly prolific authors}

Table 5 shows the high prolific author during the year of 2015-2019; with high intellectual persons are resources or asset of any institution the author contribution of his/her intellectual leads to the research productivity in any organizations, hence table 4 highlighted the most prolific author. The top productive author was Sekar N (194 articles; TC 1954; h-index 22) followed by Kumar A (180 articles; TC 2785; h-index 24), Bhanage B M A (166 articles; TC 2656; h-index 27). The most prolific author was Gogate P R (123 articles; TC 2262; h-index 29).

Table 3: Year-wise research output

\begin{tabular}{lllllll}
\hline Year & Publications & TC & ACPP & h-index & Mean (TCPP) \\
\hline 2015 & 1289 & 978 & 0.759 & 51 & 17.173 & Mean (TCPY) \\
2016 & 1468 & 4662 & 3.176 & 48 & 13.117 & 3.435 \\
2017 & 1508 & 9600 & 6.366 & 42 & 7.387 \\
2018 & 1447 & 14948 & 10.330 & 31 & 3.136 & 3.562 \\
2019 & 1460 & 20671 & 14.158 & 20 & 3.777 \\
Total & $\mathbf{7 1 7 2}$ & $\mathbf{5 0 8 5 9}$ & & $\mathbf{1 9 2}$ & \\
\hline
\end{tabular}

$\mathrm{TC}=$ Total Citations, ACPP=Average Citation per Paper, TCPP= Total Citation per Paper, $\mathrm{TCPY}=$ Total Citation per Year 


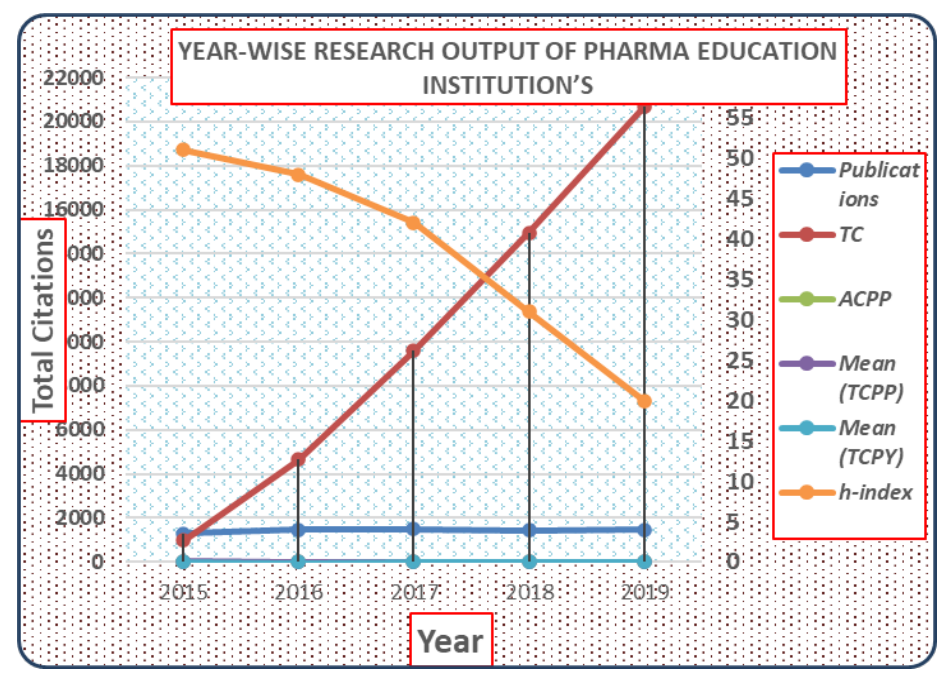

Fig. 1: Year-wise research output of pharma education institutions

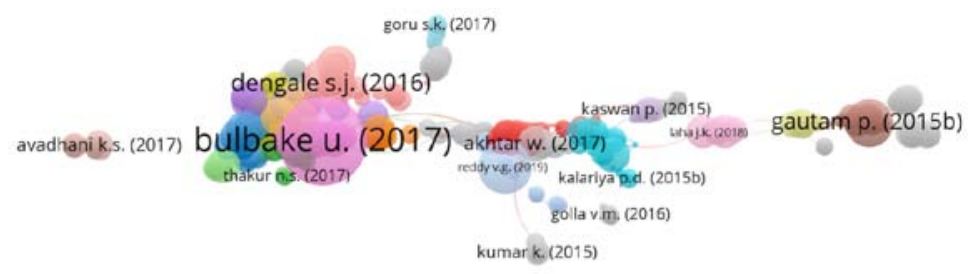

\&s vosviewer

Fig. 2: Total document citations network (2015-2019)

Table 4: Document type

\begin{tabular}{llll}
\hline S. No. & Document type & Publications & Percentage \\
\hline 1 & Article & 6067 & 84.59 \\
2 & Review & 674 & 9.40 \\
3 & Book Chapter & 258 & 3.60 \\
4 & Conference Paper & 61 & 0.85 \\
5 & Erratum & 32 & 0.45 \\
6 & Editorial & 27 & 0.38 \\
7 & Note & 15 & 0.21 \\
8 & Letter & 12 & 0.17 \\
9 & Short Survey & 12 & 0.17 \\
10 & Book & 5 & 0.07 \\
11 & Data Paper & 3 & 0.04 \\
12 & Retracted & 1 & 0.01 \\
13 & Undefined & 5 & 0.07 \\
\hline
\end{tabular}

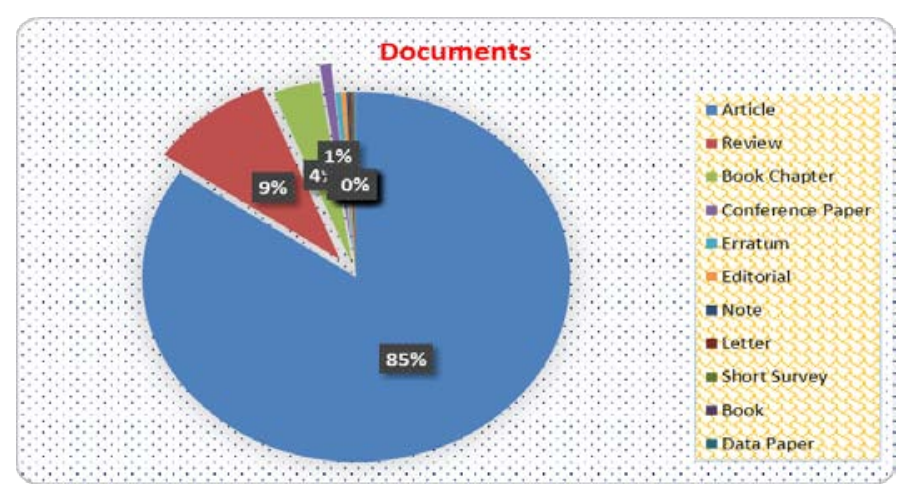

Fig. 3: Type of documents 
Table 5: Highly prolific authors

\begin{tabular}{|c|c|c|c|c|c|c|}
\hline Author & NP & TC & ACPP & h-index & g-index & m-index \\
\hline Sekar N & 194 & 1954 & 10.072 & 22 & 29 & 3.667 \\
\hline Kumar A & 180 & 2785 & 15.472 & 24 & 44 & 4.000 \\
\hline Bhanage B M & 166 & 2656 & 16.000 & 27 & 42 & 4.500 \\
\hline Sriram D & 130 & 1351 & 10.392 & 20 & 24 & 3.333 \\
\hline Gogate P R & 123 & 2262 & 18.390 & 29 & 38 & 4.833 \\
\hline Katare O P & 119 & 2047 & 17.202 & 25 & 35 & 4.167 \\
\hline Singh B & 115 & 1700 & 14.783 & 24 & 33 & 4.000 \\
\hline Jain S & 108 & 1360 & 12.593 & 22 & 28 & 3.667 \\
\hline Kamal A & 104 & 1446 & 13.904 & 21 & 30 & 3.500 \\
\hline Rathod V K & 100 & 1644 & 16.440 & 24 & 35 & 4.000 \\
\hline Yadav G D & 92 & 885 & 9.620 & 15 & 22 & 2.500 \\
\hline Singh S & 88 & 712 & 8.091 & 14 & 19 & 2.333 \\
\hline Bharatam P V & 82 & 740 & 9.024 & 15 & 20 & 2.500 \\
\hline Kumar R & 78 & 1016 & 13.026 & 16 & 29 & 2.667 \\
\hline Kumar S & 80 & 925 & 11.563 & 14 & 27 & 2.333 \\
\hline Sharma G & 79 & 1265 & 16.013 & 20 & 29 & 3.333 \\
\hline Kumar V & 79 & 822 & 10.405 & 16 & 23 & 2.667 \\
\hline Sharma S & 78 & 2244 & 28.769 & 17 & 46 & 2.833 \\
\hline Yogeeswari P & 75 & 959 & 12.787 & 19 & 23 & 3.167 \\
\hline Singhal R S & 70 & 760 & 10.857 & 16 & 24 & 2.667 \\
\hline
\end{tabular}

$\mathrm{NP}=$ No. of Publications, $\mathrm{TC}=$ Total Citations, $\mathrm{ACPP}=$ Average Citation per Paper

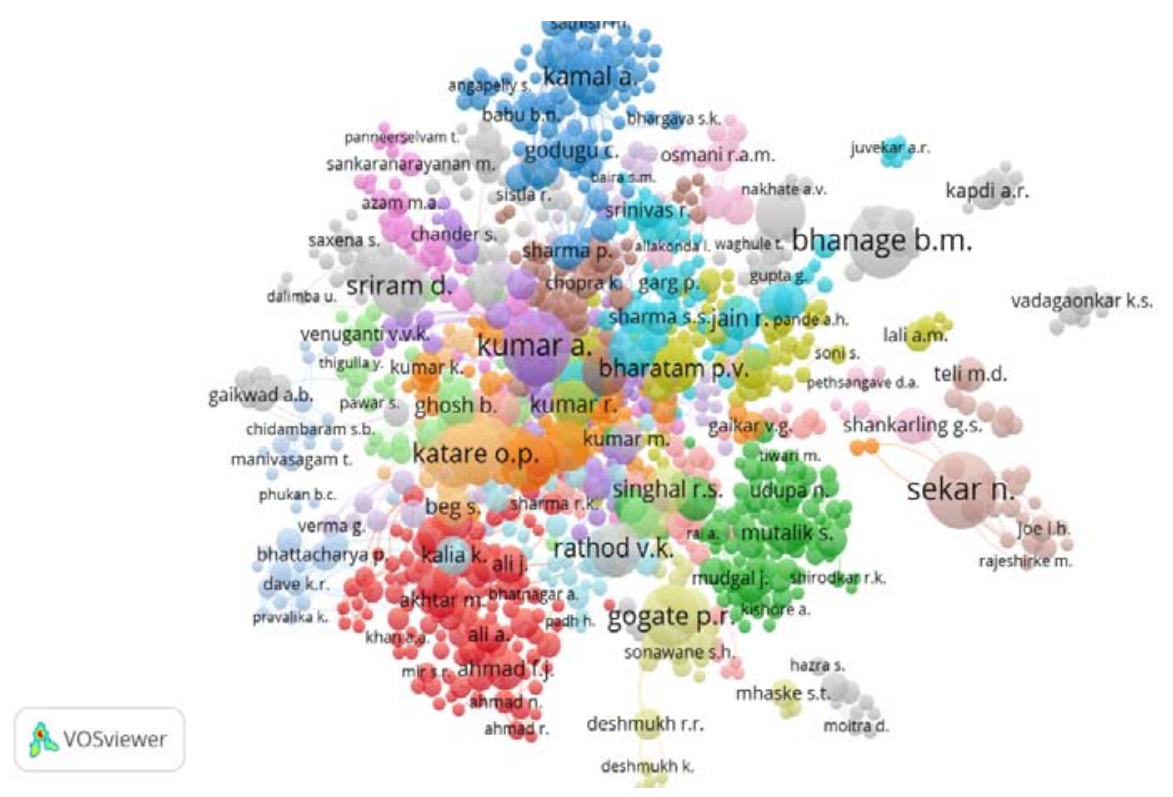

Fig. 4: Collaborative authors' network

\section{Most preferred sources for publication}

The topmost preferred source title for publication used by the pharm institutions to publish their work in well-reputed journal publications was listed in table 6 results that RSC Advance topped in the list of 217 papers of total citation count of 2508 with the h-index of 24, followed by Chemistry select of 143 papers of 739 total citation count and Ultrasonic Sonochemistry of 95 papers of 2159 total citation and highest in h-index of 30.

\section{Top funding agencies}

In institutions, funding plays a very big impact on research and development activities. The top important funding agencies which have listed may include Government and Private funding agencies that have contributed a major role in funding from both National and International agencies that have made enormous contributions and supported in $\mathrm{R}$ and $\mathrm{D}$ activities towards innovation activities.

Table 7 analyzed the top funding agencies, the major three national and state agencies are 'University Grant Commission (UGC)' funded for 609 publications followed by the Department of Science and Technology of Kerala funded for 491 publications, Department of Science and Technology, Ministry of Science and Technology, India funded for 292 publications. The top International funding agency 'Bangladesh Council of Scientific and Industrial Research' funded 233 publications.

\section{Most cited papers}

Table 8 resulted in the most cited papers among the pharmacy institutes in the list. Among the top 20 papers, one paper has the citation of 1400; i.e. Shao, yinan, et al,,(TC 1400; TCPY 233.333) on the title of "Advances in molecular quantum chemistry contained in the Q-Chem 4 program package" in the 'Journal of Molecular Physics' in 2014 followed by Kumar, A, and Singh, A.,(TC 608; TCPY 101.333) in 2015 on the title of "A review on Alzheimer's disease pathophysiology and its management: an update" in the Journal of Pharmacological reports; "Liposomal formulations in clinical use: an updated review" by Bulbuke, Upendra et al., (TC 438; TCPY 109.500) in 2017 in MDPE of Pharmaceutical Journal. 
Table 6: Most preferred sources for publication

\begin{tabular}{|c|c|c|c|c|c|}
\hline Source & NP & TC & h-index & g-index & m-index \\
\hline RSC Advances & 217 & 2508 & 24 & 30 & 4.000 \\
\hline Chemistryselect & 143 & 739 & 14 & 16 & 2.800 \\
\hline Ultrasonics Sonochemistry & 95 & 2159 & 30 & 38 & 5.000 \\
\hline European Journal of Medicinal Chemistry & 84 & 2174 & 25 & 42 & 4.167 \\
\hline International Journal of Biological Macromolecules & 77 & 1460 & 21 & 32 & 3.500 \\
\hline AAPS Pharmscitech & 76 & 679 & 14 & 19 & 2.333 \\
\hline International Journal of Pharmaceutics & 75 & 1568 & 23 & 35 & 3.833 \\
\hline New Journal of Chemistry & 75 & 665 & 14 & 20 & 2.333 \\
\hline Research Journal of Pharmacy and Technology & 75 & 52 & 4 & 4 & 0.667 \\
\hline Bioorganic and Medicinal Chemistry Letters & 74 & 975 & 19 & 23 & 3.167 \\
\hline Tetrahedron Letters & 68 & 727 & 16 & 22 & 2.667 \\
\hline Bioorganic Chemistry & 66 & 910 & 15 & 26 & 2.500 \\
\hline Drug Delivery & 57 & 1425 & 26 & 34 & 4.333 \\
\hline Journal of Organic Chemistry & 52 & 863 & 18 & 25 & 3.000 \\
\hline ACS Omega & 51 & 330 & 9 & 14 & 2.250 \\
\hline Organic and Biomolecular Chemistry & 51 & 578 & 16 & 20 & 2.667 \\
\hline Industrial and Engineering Chemistry Research & 47 & 228 & 9 & 11 & 1.500 \\
\hline Journal of Pharmaceutical and Biomedical Analysis & 47 & 393 & 11 & 15 & 1.833 \\
\hline Journal of Fluorescence & 45 & 309 & 10 & 14 & 1.667 \\
\hline Journal of Drug Delivery Science and Technology & 44 & 346 & 12 & 16 & 2.000 \\
\hline
\end{tabular}

NP=No. of Publications, $\mathrm{TC}=$ Total Citations

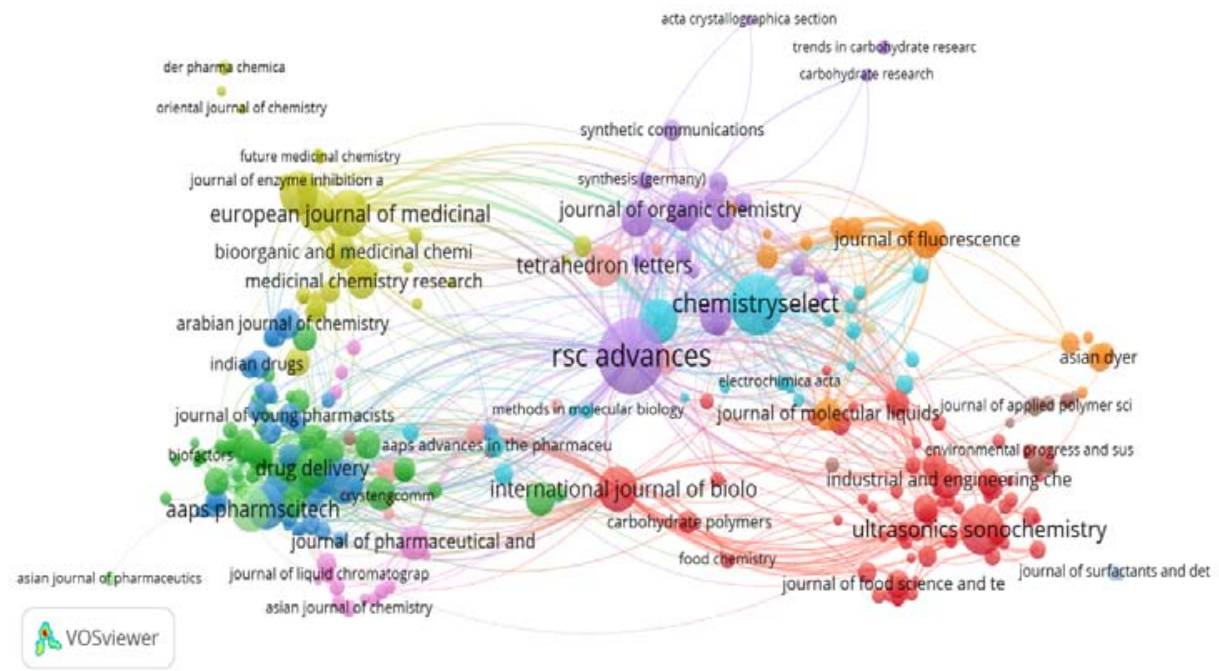

Fig. 5: Sources citation network

Table 7: Top funding agencies

\begin{tabular}{|c|c|}
\hline Funding agencies & NP \\
\hline University Grants Commission & 609 \\
\hline Department of Science and Technology, Government of Kerala & 491 \\
\hline Department of Science and Technology, Ministry of Science and Technology, India & 292 \\
\hline Science and Engineering Research Board & 266 \\
\hline Bangladesh Council of Scientific and Industrial Research & 233 \\
\hline University Grants Committee & 214 \\
\hline Department of Biotechnology, Government of West Bengal & 190 \\
\hline Council of Scientific and Industrial Research, India & 187 \\
\hline Indian Council of Medical Research & 120 \\
\hline Department of Science and Technology, Government of West Bengal & 77 \\
\hline All India Council for Technical Education & 75 \\
\hline Council of Scientific and Industrial Research & 65 \\
\hline Department of Science and Technology, Ministry of Science and Technology & 51 \\
\hline Manipal University & 38 \\
\hline Birla Institute of Technology and Science, Pilani & 37 \\
\hline Department of Biotechnology, Ministry of Science and Technology, India & 36 \\
\hline National Institutes of Health & 35 \\
\hline Department of Atomic Energy, Government of India & 26 \\
\hline Alexander von Humboldt-Stiftung & 25 \\
\hline Defence Research and Development Organisation & 24 \\
\hline
\end{tabular}


Table 8: Most cited papers

\begin{tabular}{|c|c|c|c|}
\hline Paper & DOI & TC & TCPY \\
\hline SHAO Y, 2015, MOL PHYS & $10.1080 / 00268976.2014 .952696$ & 1400 & 233.333 \\
\hline KUMAR A, 2015, PHARMACOL REP & 10.1016/j. pharep.2014.09.004 & 608 & 101.333 \\
\hline BULBAKE U, 2017, PHARMACEUTICS & $10.3390 /$ pharmaceutics 9020012 & 438 & 109.500 \\
\hline WAGENMAKERS EJ, 2018, PSYCHONOM BULL REV & $10.3758 / \mathrm{s} 13423-017-1323-7$ & 386 & 128.667 \\
\hline AFZAL 0, 2015, EUR J MED CHEM & 10.1016/j. ejmech.2014.07.044 & 308 & 51.333 \\
\hline CHEN C, 2019, NATURE SUSTAIN & $10.1038 / \mathrm{s} 41893-019-0220-7$ & 244 & 122.000 \\
\hline BISWAS S, 2016, EUR J PHARM SCI & 10.1016/j. ejps.2015.12.031 & 224 & 44.800 \\
\hline PRABHU RH, 2015, INT J NANOMED & 10.2147/IJN. S56932 & 204 & 34.000 \\
\hline BAGAL DB, 2015, ANGEW CHEM INT ED & 10.1002/anie. 201501880 & 188 & 31.333 \\
\hline BYRNE C, 2018, J ENVIRON CHEM ENG & $10.1016 /$ j. jece.2017.07.080 & 178 & 59.333 \\
\hline D'SOUZA AA, 2015, J CONTROL RELEASE & 10.1016/j. jconrel.2015.02.022 & 172 & 28.667 \\
\hline KHAN MF, 2016, EUR J MED CHEM & 10.1016/j. ejmech.2016.04.077 & 168 & 33.600 \\
\hline DENGALE SJ, 2016, ADV DRUG DELIV REV & 10.1016/j. addr.2015.12.009 & 168 & 33.600 \\
\hline MEHTA D, 2015, J WATER PROCESS ENG & 10.1016/j. jwpe.2015.07.001 & 158 & 26.333 \\
\hline GHOSH BK, 2015, POWDER TECHNOL & $10.1016 / j$. powtec.2014.09.027 & 149 & 24.833 \\
\hline MUHEEM A, 2016, SAUDI PHARM J & $10.1016 /$ j. jsps.2014.06.004 & 148 & 29.600 \\
\hline YAMJALA K, 2016, FOOD CHEM & 10.1016/j. foodchem.2015.07.085 & 147 & 29.400 \\
\hline PERICHERLA K, 2015, SYNTHESIS & $10.1055 / s-0034-1380182$ & 142 & 23.667 \\
\hline AKHTAR J, 2017, EUR J MED CHEM & 10.1016/j. ejmech.2016.09.023 & 136 & 34.000 \\
\hline GAUTAM P, 2015, CATAL SCI TECHNOLOGY & $10.1039 / \mathrm{c} 5 \mathrm{cy} 00691 \mathrm{k}$ & 132 & 22.000 \\
\hline
\end{tabular}

Table 9: Most productive and most cited countries

\begin{tabular}{|c|c|c|c|c|}
\hline Country production & & Most cited countries & & \\
\hline Country & TP & Country & TC & AC \\
\hline India & 13575 & India & 30214 & 10.140 \\
\hline USA & 528 & USA & 736 & 22.300 \\
\hline Saudi Arabia & 353 & Netherlands & 433 & 108.250 \\
\hline Australia & 209 & Saudi Arabia & 429 & 13.000 \\
\hline Malaysia & 126 & France & 328 & 27.330 \\
\hline Germany & 110 & Germany & 324 & 24.920 \\
\hline United Kingdom & 93 & Korea & 249 & 14.650 \\
\hline Canada & 81 & Malaysia & 249 & 16.600 \\
\hline China & 80 & Israel & 183 & 26.140 \\
\hline France & 79 & Ireland & 178 & 178.000 \\
\hline Japan & 70 & United Kingdom & 126 & 18.000 \\
\hline South Korea & 52 & South Africa & 120 & 24.000 \\
\hline Oman & 50 & Australia & 117 & 14.620 \\
\hline Brazil & 48 & Canada & 114 & 16.290 \\
\hline Spain & 44 & China & 81 & 20.250 \\
\hline Israel & 40 & Singapore & 79 & 15.800 \\
\hline Finland & 34 & Georgia & 74 & 24.670 \\
\hline Italy & 34 & Japan & 60 & 20.000 \\
\hline South Africa & 33 & Hungary & 56 & 56.000 \\
\hline Singapore & 26 & Italy & 55 & 7.860 \\
\hline
\end{tabular}

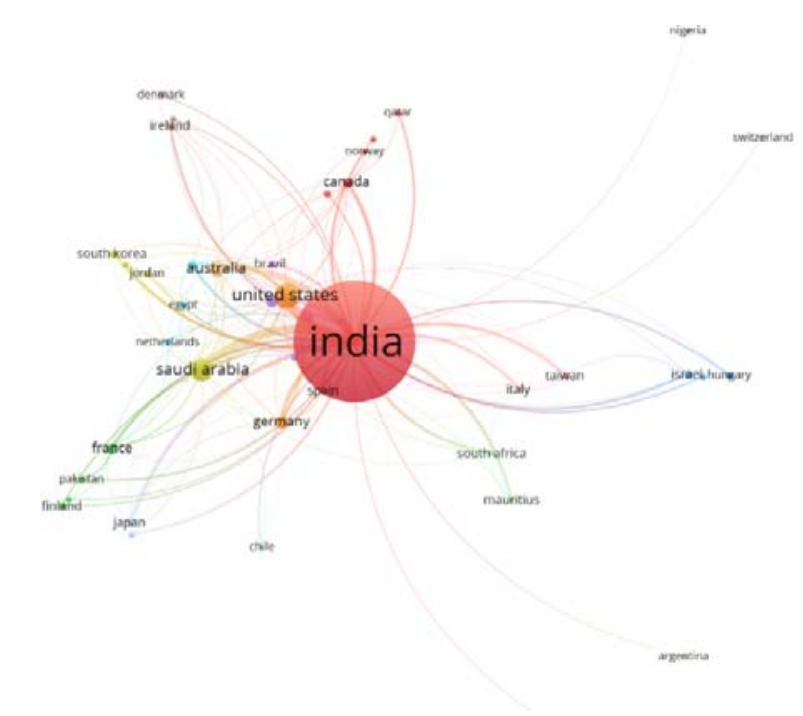

Fig. 6: Countries citation network 


\section{Most productive and most cited countries}

NIRF top 9 ranked Pharma institutions have collaborated with various countries, where the USA placed top in the table with 528 publications followed by Saudi Arabia, Australia, Malaysia, Germany, United Kingdom, Canada, China, France, Japan, South Korea, Oman, Brazil, Spain, Israel, Finland, Italy, South Africa, and Singapore respectively among the top twenty countries. Fig. 8 showing the countries' citation network. It can be seen that the scholars got the maximum citations from India with 30214 citations and followed by the USA, Netherlands, Saudi Arabia, France, Germany, Korea,
Malaysia, Israel, Ireland, United Kingdom, South Africa, Australia, Canada, China, Singapore, Georgia, Japan, Hungary, and Italy.

\section{Highly prolific keywords}

Table 9 denotes occurrences of keywords used in the papers. In all, 40691 keywords have been figured in 7172 papers. Of these keywords, Article has appeared (3235) times, followed by Nonhuman (2132) times, Controlled Study (1988), Human (1811), Chemistry (1701), and Priority Journal (1611) respectively. All Keywords Network showed in fig. 9 and 10.

Table 10: Prolific keywords

\begin{tabular}{|c|c|}
\hline Keyword & Frequency \\
\hline Article & 3235 \\
\hline Nonhuman & 2132 \\
\hline Controlled Study & 1988 \\
\hline Human & 1811 \\
\hline Chemistry & 1701 \\
\hline Priority Journal & 1611 \\
\hline Unclassified Drug & 1559 \\
\hline Animals & 1419 \\
\hline Animal & 1415 \\
\hline Metabolism & 1317 \\
\hline Humans & 1274 \\
\hline Animal Experiment & 1118 \\
\hline Male & 978 \\
\hline In vitro Study & 977 \\
\hline Rat & 860 \\
\hline Animal Model & 796 \\
\hline Particle Size & 707 \\
\hline Synthesis & 664 \\
\hline Drug Delivery System & 652 \\
\hline Drug Effects & 640 \\
\hline
\end{tabular}

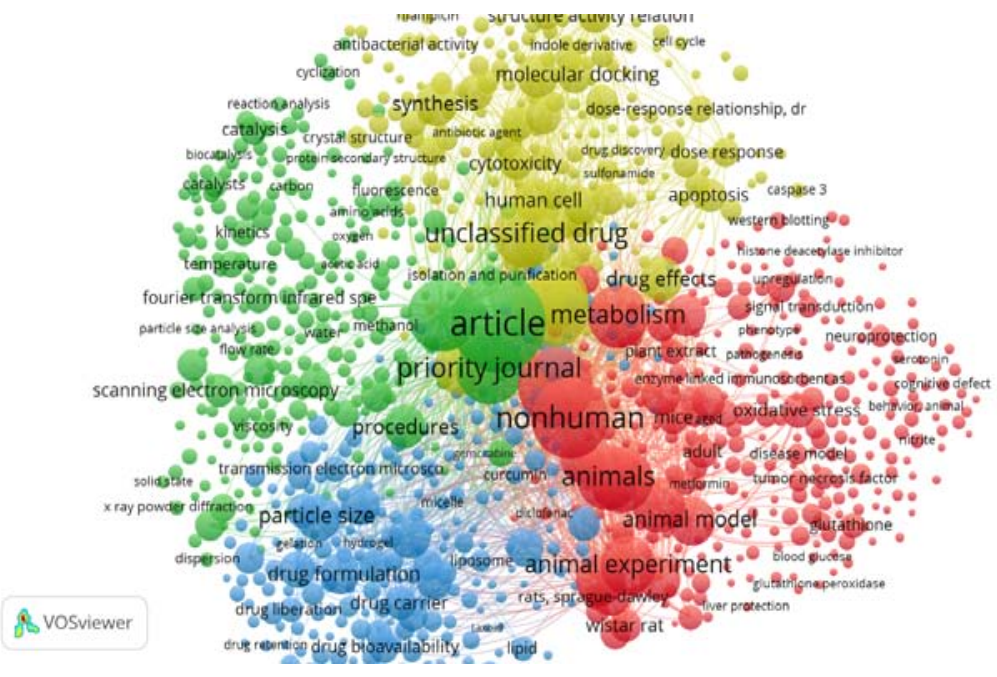

Fig. 7: All keywords network

\section{CONCLUSION}

The important significance of NIRF is to know the top institutions within India. The preeminent branding exercise with some definite parameters will be helpful for institutes to improve the quality and services offered by them [22]. It is a self-participating and domainspecific system which helps in the free advertisement of institutions within India and the world. Based on the NIRF ranking system numerous works have been performed on technical institutions, universities, and single concerted institutional studies. The research output of pharma institutions was less. Hence, it helps forthcoming students to identify India's leading higher education institution in their field in response to the high demand for subject-level assessments.

\section{ACKNOWLEDGMENT}

Authors are thankful to Dr. Chaman Sab M, librarian, Dr. Vitthal Bagalkoti Library and Information Officer, for their valuable suggestions during the study. Authors are also thankful to Miss Vidyashree T, Assistant Professor for her valuable support during the study.

\section{FUNDING}

This research paper has not received any type of grant from any funding agencies.

\section{AUTHORS CONTRIBUTIONS}

Mr. Mallikarjun Kappi conceived the idea and developed the research article and prepared the tables and used VOSviewer and 
Biblioshiny software tool for constructing and various visualizing bibliometric networks, and co-authorship relations. Mr. Madhu S contributed to the literature review, analysis, and interpretation part, wrote limitations and scope for future research, and the manuscript was reviewed and edited under the guidance and supervision of Dr. Balabhim Sankrappa Biradar.

\section{CONFLICT OF INTERESTS}

The authors declare no conflict of interest.

\section{REFERENCES}

1. Reddy KS, Xie E, Tang Q. Pacific science review b: humanities and social sciences rankings: a case of India and comparison with China. Pacific Sci Rev A Nat Sci Eng 2016;2:1-21.

2. Sangam SL, Bagalkoti VT. Rankings of Indian Universities: a scientometrics analysis. Proc $10^{\text {th }}$ Int CALIBER; 2015. p. 18291.

3. Prathap G. The performance of research-intensive higher educational institutions in India. Curr Sci 2014;107:389-96.

4. NKS, Mathew KS, Cherukodan S. Impact of scholarly output on university ranking. Glob Knowledge Mem Commun 2018:67:154-65.

5. Vignesh M, Ganesh GNK. Current status, challenges and preventive strategies to overcome data integrity issues in the pharmaceutical industry. Int J Appl Pharm 2020;12:19-23.

6. Kumar A, Tiwari S, Chauhan AK, Ahirwar R. Impact of NIRF on research publications: a study on top 20 (ranked) Indian Universities. Collnet J Sci Inf Manag 2019;13:219-9.

7. Marisha, Banshal SK, Singh VK. Research performance of central universities in India. Curr Sci 2017;112:2198-207.

8. Mukherjee B. Ranking Indian universities through research and professional practices of national institutional ranking framework (NIRF): a case study of select central universities in India. J Indian Libr Assoc 2016;52:93-107.

9. Gourikeremath G, Hiremath RS. A comparative study of university of mysore and karnatak university in science. Res Output Citation Impact During 2002-16 2020;56:75-83.
10. Kappi M, Chaman Sab M MB, Bagalkoti DVT. Research productivity of NIRF 2020 top indian law institutions. In: Rai DP, Singh DA, Arjun D, Prasad S, Bansal DV. editors. Changing dimensions of education and librarianship during COVID-19. Bhagalpur: AKB Publication; 2020. p. 48-68.

11. Pradhan B, Ramesh DB. Scientometric analysis of research publications of six. Indian Institutes Technol 2018;65:50-6.

12. Das TK. Bibliometric analysis of research publications of IITs: a study based on scopus. J Acad Librariansh 2019;20:105-23.

13. Kumar, Satish, Senthilkumar R, Kumar S, Senthilkumar R. Scientometric mapping of research output of NIRF first ranked institute of India: IISc, Bangalore. Libr Philos Pract; 2019.

14. Lwoga ET, Sangeda RZ, Sife AS. Online visibility of pharmacy research in tanzania: a scientometric study. Int J Pharm Pharm Sci 2017;9:72.

15. Pal JK, Sarkar S. Evaluation of institutional research productivity. DESIDOC J Library Information Technol 2020;40:406-17.

16. Aria M, Cuccurullo C. bibliometrix: an r-tool for comprehensive science mapping analysis. J Informetr 2017;11:959-75.

17. van Eck NJ, Waltman L. Software survey: VOSviewer, a computer program for bibliometric mapping. Scientometrics 2010;84:523-38.

18. Lawani SM. Quality, collaboration and citations in cancer research a bibliometric study. [Internet]. Florida State University; 1980. Available from: https://www.elibrary.ru/item.asp?id=7306719. [Last accessed on 01 Mar 2021].

19. Subramanyam K. Bibliometric studies of research collaboration: a review. J Inf Sci 1983;6:33-8.

20. Ajiferuke I, Burell Q, Tague J. Collaborative coefficient: a single measure of the degree of collaboration in research. Scientometrics 2021;14:421-33.

21. Savanur K, Srikanth R. Modified collaborative coefficient: a new measure for quantifying the degree of research collaboration. Scientometrics 2010;84:365-71.

22. Palsokar G, Tajne M. Postgraduate research in pharmaceutical sciences in India: a survey of select pharmacy professionals. Int J Curr Pharm Res 2017;9:161. 